Monográfico / Monographic

\title{
Conmemorando a Erik Olin Wright
}

\author{
Julio Carabaña Morales \\ Universidad Complutense de Madrid, España \\ carabanya@ccedu.ucm.es
}

Erik Olin Wright murió el 23 de Enero de 2019. De estar ahí, lejano pero accesible, pasó a ser alguien cuya existencia ha quedado reducida a memoria. Jorge Sola me escribió el primero. Luego vinieron otros -Natalia García-Pardo, Olga Salido, Miguel Caínzos- y fuimos compartiendo recuerdos. Hablamos de ampliar esta conmemoración, y propusimos una sesión en el Congreso de la FES (Valencia, Julio de 2019), pero llegamos tarde. Pensamos entonces en dejar por escrito en la RES al menos un rastro, un reflejo, de la influencia que había tenido entre nosotros. Encontramos la mejor acogida. Acordamos que serían cuatro o cinco artículos, con una breve presentación. Fue fácil encontrar colegas que aceptaran gustosos la tarea.

Pareció buena idea reunirnos para discutir los borradores, y para que los tres de Madrid no tuviéramos ventaja sugerimos al Departamento de Sociología Aplicada de la UCM cubrir los gastos de los tres de fuera. La directora, Margarita Barañano, adoptó la reunión como una actividad pública del Departamento. Bien situada para valorar la importancia de Wright desde su dedicación a la Teoría Sociológica, seguro que recordó además aquel cinco de marzo de 1993 cuando llevó a sus alumnos a una conferencia de Wright sobre 'Reconstructing Marxism' en la Facultad. Y así ocurrió que el homenaje que se había reducido a unos escritos se amplió a un acto público que, organizado por Jorge Sola, reunió a profesores y alumnos el jueves 30 de enero de 2020 en la UCM y al día siguiente en la UNED.

Los cuatro artículos que vienen a continuación constituyen un homenaje por así decirlo indirecto; son cuatro investigaciones, más empíricas unas y más teóricas otras, relacionadas con los campos que Erik Wright más trabajó y en los fue más influyente, desde la teoría marxista de las clases que lo llevó aún muy joven a los manuales de Sociología a los trabajos sobre ‘utopías reales' a los que se dedicó más en los últimos años, pasando por su interés permanente y transversal por las cuestiones del feminismo y la epistemología de las Ciencias Sociales. Aparecen en el orden que me ha parecido más indicado para el lector que no conozca la obra de Wright. El trabajo de Inés Campillo presenta y evalúa las aportaciones de Wright al estudio de las relaciones de género, tanto desde la teoría de las clases, en su primera época, como desde la búsqueda de utopías reales de la segunda, y por ello ofrece también una visión general de la obra de Wright. Jorge Sola discute las posibilidades y las dificultades de las 'utopías reales'. Miguel Caínzos amplía y profundiza el trabajo de Wright sobre el 'techo de cristal' con un exhaustivo análisis de datos españoles. He dejado para el final el trabajo de José Antonio Noguera porque se centra en una cuestión muy general, las tensiones inherentes al programa de separar el marxismo de la dialéctica y someterlo a las exigencias de la ciencia social convencional. No ha llegado a tiempo el trabajo de José S. Martínez García, que trata de las clases en Marx, Wright y Bourdieu, un campo que apenas queda cubierto por esta nota. 
Imagen 1. Cartel de las Jornadas en homenaje a Erik Olin Wright.
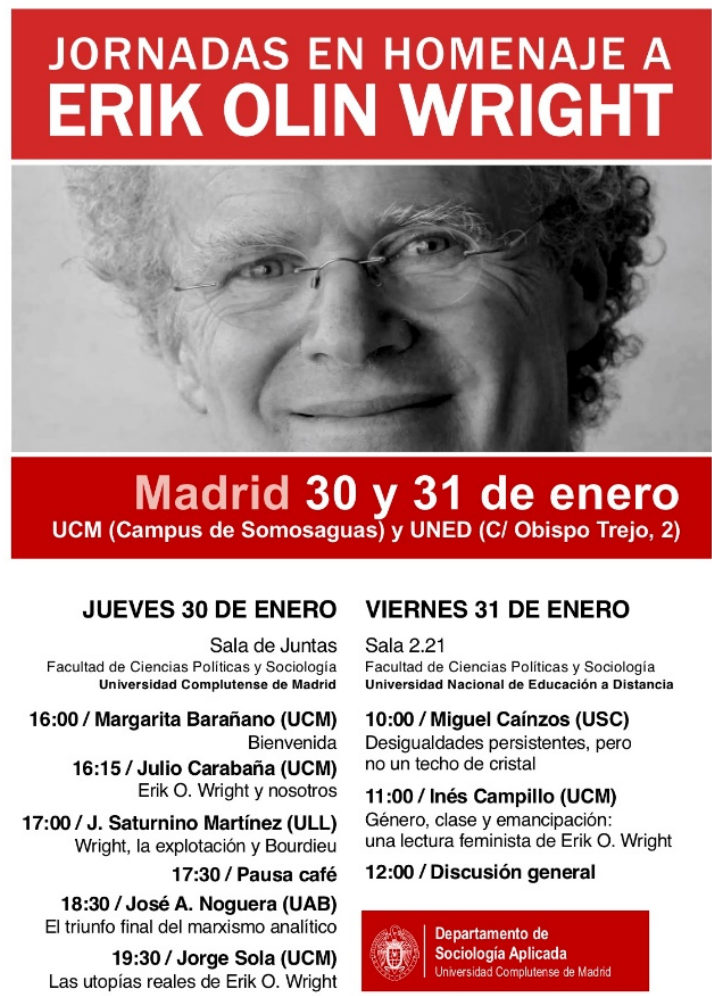

El lector ya habrá colegido que yo no voy a honrar la memoria de Wright con un trabajo académico, y puede que se pregunte por mis títulos para atribuirme el papel de coordinador, rol sospechoso de estar en una posición contradictoria de clase o incluso de establecer una relación explotadora con los coordinados al apropiarse un bien de organización. Puedo justificarme por lo mucho que lo admiré desde muy pronto y por haber dirigido la réplica de su proyecto sobre clases en España ${ }^{1}$.

Me traje de mi primer viaje a Estados Unidos en 1974 un ejemplar del Berkeley Journal of Sociology, con el artículo de Wright sobre "Lenin and Weber on Burocracy" y leí atentamente sus escritos sobre clases, traducidos algunos en En Teoría y en su sucesora Zona Abierta, ambas dirigidas por Ludolfo Paramio. Quedé fascinado por lo mismo que fascinó de Wright a tantos otros, por un lado su brillantez y por otro su rigor. ¿Cuánta prosa no llevaba yo leída por entonces sobre el problema de las nuevas clases medias en el marxismo? La solución de Wright era el huevo de Colón: son, efectivamente, posiciones contradictorias de clase. Nada nuevo, pues ya la propia pequeña burguesía puede verse como siendo a la vez su propio capitalista y su propio empleado. Bastaba con generalizar la idea, de modo que cualquier

1 Cf. Carabaña et al. (1992). El Proyecto fue financiado por el Instituto de la Mujer, el INE, la Comunidad de Madrid y la CICYT, y llevado a cabo en el IESA del CSIC. 
par de clases simples pudiera dar lugar a posiciones contradictorias de clase. Se le podía haber ocurrido a cualquiera, pero se le ocurrió a Wright, que una vez puesta en marcha su máquina lógica no dejaba nada fuera del proceso.

Por impresionante que fuera esta coherencia teórica, era más chocante todavía su compromiso con lo empírico. Si el marxismo pretendía ser científico, tenía que renunciar a tener un criterio de cientificidad propio, la dialéctica, y someterse a la contrastación empírica de hipótesis derivadas de sus teorías. Wright (1979) lo intentó en su tesis doctoral, Class structure and income determination, un terreno de entrada pantanoso tras haber advertido previsoramente Marx que las clases sociales no tenían que ver con el tamaño de la bolsa, sino con las relaciones de producción. Pero así y todo, Wright se enfangó en él, saliendo del desafio más que limpio, brillante.

A fines de los setenta contrastar las hipótesis con datos de encuesta en vez de con experiencias históricas era totalmente insólito entre marxistas. Había dos sociologías, la marxista y la burguesa. La burguesa se afanaba en producir proposiciones con apariencia de 'leyes' sociales e hipótesis inmediatamente contrastables sobre asuntos triviales de la vida diaria, como el consumo de automóviles, la asistencia a la Iglesia, o la intención de voto, al servicio del Estado, de empresas, de particulares o de potencias todavía más oscuras. La marxista producía y revisaba interpretaciones sobre la única cuestión realmente importante, que era la revolución proletaria. Su actividad investigadora, si sobrepasaba la exégesis de los fundadores, se orientaba a calibrar el avance del proceso: el desarrollo de las contradicciones del capitalismo, la profundidad de las crisis, el grado de conciencia de la clase obrera, las estrategias para alienarla mediante el consumo, la publicidad o el fútbol, la disposición de las otras clases a formar alianzas. Y hete aquí que el joven sociólogo de Berkeley quería hacer las dos cosas al mismo tiempo y mostrar la superioridad de la teoría marxista con los métodos propios de la sociología burguesa. Asombroso.

Lo imité cuanto pude. Por influjo de Ubaldo Martínez-Lázaro yo intentaba por aquellos años terminar una tesis doctoral sobre movilidad social, usando el modelo de logro de estatus de Blau y Duncan. Siguiendo a Wright -más concretamente, siguiendo 'Marxist Class Categories and Income Inequality', el artículo que publicó junto con su amigo Luca Perrone en la American Sociological Review en 1977 , dos años antes de que apareciera su tesis en Academic Press- intenté encontrar diferencias en el poder predictivo de diversos esquemas de clases. El resultado fue decepcionante. El terrible aparato luminoso y sonoro de la discusión teórica paría un magro ratoncillo en los modelos predictivos, y las revolucionarias proposiciones marxistas rara vez superaban las pruebas del SPSS.

Pero yo analizaba una muestra muy pequeña, que solo soportaba bien unas pocas variables. Unos años más tarde me propuse conseguir una muestra más grande para replicar en España el Proyecto sobre Clases que Wright impulsaba, extendido ya a más de diez países, cuyos primeros análisis publicó en Classes (Wright, 1985). El Proyecto sobre Estructura, Conciencia y Biografía de Clase (ECBC) duró formalmente de 1987 a 1996 y durante esos años la comunicación con Wright fue constante. A mi admiración por su brillantez y su rigor se sumó entonces la que me produjo su capacidad de organización y su gentileza personal. Cuando llegamos nosotros, más de quince equipos de distintos países se habían unido ya al proyecto y otros se continuaban uniendo, lo que suponía un enorme trabajo de coordinación. En concreto, había que renovar el cuestionario para atender novedades teóricas y, en particular, la participación de la Unión Soviética. Erik me dedicó tres días en Wisconsin en el verano de 1989 y luego nos reunimos una semana en Moscú, en la Navidad de 1990, con los colegas soviéticos. Después organizó la parte académica de la VI Conferencia del Proyecto (norteamericanos, australianos, fineses, alemanes, rusos...) en el verano de 1991 en Granada, incluyendo el fin de fiesta con él tocando el violín (fiddle) y nosotros bailando la 'square dance'; más la coda de una excursión a Sierra Nevada en furgoneta 
('more fun'), de la que su vocación de cuenta-cuentos sacó un divertido relato para sus hijas. Más tarde vino invitado a nuestro Seminario en marzo de 1993, donde nos habló de Reconstructing Marxism (Wright, 1992) -fue entonces, creo, cuando se llevó de recuerdo un txistu y un tamboril firmado por todos nosotros, pues quería avanzar de simple fiddler a doble instrumentista-. Nos visitó otra vez para un Seminario en la Fundación Argentaria en Octubre de 1994, que terminó publicado en un libro (Carabaña, 1995) ..., Parecía capaz de organizarlo todo, o, mejor dicho, incapaz de dejar algo sin organizar, poniendo en la vida práctica la misma claridad que en sus exposiciones, y también la misma aspiración de armonía y de belleza.

Con el Proyecto ECBC ${ }^{2}$ llegamos todavía a tiempo, pero también llegamos tarde. No estaba claro que los resultados empíricos de todo este esfuerzo estuvieran mereciendo la pena, como luego Wright (1997) escribiría en el prefacio de Class Counts. O, peor aún, hacían más dificil justificar la insistencia en el marxismo, tanto en general como ante los otros participantes en el Proyecto, la mayor parte de los cuales no eran marxistas. Debates on Classes (Wright, 1989) terminaba repensando, de nuevo, el concepto de clase. Respondiendo a Rose y Marshall, y tras reconocer la semejanza entre sus esquemas y los basados en Weber, Wright (1989) se pregunta por qué mantener sobre la teoría constricciones del tipo de que el concepto de clase debe basarse en la explotación. Responde que la razón principal eran los lazos entre la tradición marxista y el cambio social emancipatorio (pp. 321-322), un argumento poco convincente en los primeros años noventa, cuando la Unión Soviética se derrumbaba ella sola ante la estupefacción del mundo. Así que si por un lado el estudio de las clases no salvaba al marxismo como proyecto emancipatorio, por otro el mantenimiento del marxismo era un estorbo para el estudio de las clases. Wright resolvió el problema con su integridad característica, dando a César lo que parecía del César, pero manteniendo para Dios lo que creía de Dios. A los rivales sociológicos del marxismo los acabó reconociendo como iguales y construyéndoles en Understanding Class (Wright, 2015) una acogedora estructura teórica en la que cada cual tenía su lugar. Pero él perdió interés en el estudio de las clases. Los proyectos que se incorporaron en los años noventa -el español, el argentino, el portugués y el soviético entre ellos- ya no fueron incluidos en una misma base de datos ni analizados conjuntamente desde una misma perspectiva teórica. El último encuentro del Proyecto Internacional tuvo lugar en Camberra en 1997; el debate se centró en la muerte de las clases sociales. Después, cada proyecto continuó el rumbo independiente que ya había tomado.

Wright salvó la contradicción entre el compromiso con los demás y el compromiso con el conocimiento dejando atrás la teoría marxista de las clases, pero no el marxismo. Como Burawoy ha escrito,"at this point Erik could have left Marxism like so many. He would have won accolades for seeing the light, for recognizing the error of his youthful ways. That was not Erik. Instead he re-invented Marxism, suited to the times. Breaking from his class analysis, he recovered his old interest in utopian thinking" (Burawoy, 2020). Tras el Proyecto Internacional dedicó su explosivo talento y su inagotable energía a la persecución de 'utopías reales'. Ahí ya le perdí la pista.

Erik Olin Wright fue una gran persona que puso una enorme voluntad en contribuir con su brillante intelecto a explicar y mejorar el funcionamiento de la vida social. Los artículos que siguen rinden, creo, un digno homenaje a su persona abordando su obra con el rigor y la claridad de los que él fue tan alto ejemplo.

2 Juan Jesús González (1992) llevó a cabo muy pronto un análisis general de los datos, que fueron luego utilizados en las tesis doctorales de Olga Salido, Araceli Serrano, Javier Echevarría, Carmuca Gómez Bueno, Javier Vidal y Javier Noya, además de por otros autores. 


\section{REFERENCIAS}

Burawoy, M. (2020). A Tale of Two Marxisms: Remembering Erik Olin Wright, 1947-2019. New Left Review, 121, 67-98.

Carabaña, J. (1995). Desigualdad y clases sociales: un seminario en torno a Erik O Wright. Madrid: Visor-Argentaria.

Carabaña, J., González, J. J., Serrano, A., Vallejos, A., Veredas, S., Riviere, J. y Navarro, C. (1992). Informe Técnico de la Encuesta de Estructura, Conciencia y Biografía de Clase. Madrid: Comunidad de Madrid/Consejería de Economía/Departamento de Estadística.

González-Rodríguez, J. J. (1992). Clases sociales: estudio comparativo de España y la Comunidad de Madrid. Madrid: Consejería de Economía/Departamento de Estadística.

Wright, E. O. (1979). Class Structure and income Determination. New York: Academic Press.

Wright, E. O. (1985). Clases. London/New York: Verso.

Wright, E. O. (1989). The Debate on Classes. London/New York: Verso.

Wright, E. O. (1997). Class counts: Comparative studies in class analysis. Cambridge/ New York/Paris: Cambridge University Press//Maison des sciences de l'homme.

Wright, E. O. (2015). Understanding Class. London/New York: Verso.

Wright, E. O. (con Levine, A., y Sober, E.), (1992). Reconstructing Marxism. New York: Verso.

Wright, E. O. y Perrone, L. (1977). Marxist Class Categories and Income Inequality. American Sociological Review, 42(1), 32-32. 